\title{
Impact of Insulin Injection and Infusion Routines on Lipohypertrophy and Glycemic Control in Children and Adults with Diabetes
}

\author{
Asma Deeb · Layla Abdelrahman · Mary Tomy · Shaker Suliman • \\ Mariette Akle $\cdot$ Mike Smith $\cdot$ Ken Strauss
}

Received: November 18, 2018 / Published online: January 8, 2019

(C) The Author(s) 2019

\begin{abstract}
Introduction: Proper insulin injection/infusion is essential to optimize insulin absorption and action. Guidelines on insulin injection techniques are available. Lipohypertrophy (LH) is a local complication of insulin therapy, which results in erratic absorption and impaired glycemic control.

Methods: Children and adults with type 1 diabetes on insulin injection or infusion were enrolled in the study. Subjects were interviewed and filled in a questionnaire on injection/infusion routines. Sites of injection/infusion were examined by trained diabetes educators, and capillary HbA1c was obtained.
\end{abstract}

Enhanced Digital Features To view enhanced digital features for this article go to https://doi.org/10.6084/ m9.figshare.7485284.

A. Deeb $(\bowtie) \cdot$ L. Abdelrahman · M. Tomy ·

S. Suliman · M. Akle

Paediatric Endocrinology Department,

Mafraq Hospital, P O Box 2951, Abu Dhabi,

United Arab Emirates

e-mail: adeeb@seha.ae

M. Smith

BD Diabetes Care, Oxford Science Park,

Oxford OX4 4DQ, UK

K. Strauss

BD Diabetes Care, POB 13, Erembodegem-Dorp 86,

9320 Erembodegem, Belgium
Results: One hundred sixty-nine subjects (104 children) with type 1 diabetes were enrolled; 119 were on multiple daily injection (MDI) and 50 on insulin pump therapy. Seventy-two percent and $82 \%$ of children and adults, respectively, rotate site at every injection; $78 \%$ of pump users change infusion set and $74 \%$ rotate site at 2-3 days. Thirty-nine percent and $32 \%$ of children and adults had LH. HbA1c was lower in children and adults with no LH $(P<0.001)$. An association was seen between $\mathrm{LH}$ and rotation frequency in children $(P=0.026)$. LH was the most common skin complication in the MDI group, while nodules, allergy marks and hyperpigmentation were seen in pump users.

Conclusion: Proper injection/infusion routines impact glycemic control and skin health. Education and examination of injection sites remain a crucial part of diabetes management.

Keywords: Complication; Infusion; Injection; Lipohypertrophy; Pump

\section{INTRODUCTION}

A dramatic evolution is currently witnessed in advancing insulin injection and infusion devices. However, inaccuracies in basic routines of delivering insulin remain a major obstacle to optimum diabetes control. Optimizing the pharmacokinetics and pharmacodynamics of insulin depends on proper insulin injection [1]. 
Guidelines and recommendations on proper insulin injection techniques are available [2]. However, various factors might interfere with concordance with these recommendations. The recently published worldwide injection technique questionnaire results revealed multiple improper injection techniques. Of those, the existence of inappropriate use of longer needles, failure to rotate injections properly and reuse of needles were observed internationally [3]. Improper injection techniques result in formation of hypertrophic tissues from needle clogging and bending, which leads to insulin crystallization, inaccurate dosing, increase in pain and insulin leakage [4]. Despite release of guidelines on injection techniques and education, there is still a high prevalence of lipohypertrophy (LH). Reasons extend to a possible poor knowledge of subcutaneous tissue anatomy and the body response to insulin injection by patients and health care professionals [5]. In addition, there might be a difference in the anatomy of structure influenced by race in multi-ethnic societies, which should be considered [5].

LH as a local complication of insulin therapy is well recognized. Despite improvements in insulin purity and the introduction of recombinant human insulin, its prevalence has remained high [3]. Histologically, the hypertrophic adipocytes are twice as large as those from normal subcutaneous areas and contain numerous small lipid droplets [6]. A recent case was reported to show a large lipohypertrophied area of a fluid reservoir detected by ultrasonography subcutaneously. Analysis of the fluid showed a 13-fold higher concentration of insulin compared with the circulating level [7]. Electron microscopic analysis revealed features suggestive of active differentiation or proliferation of adipocytes.

Although the cause of LH is not fully established, the predisposing conditions may be the injection trauma to the skin and subcutaneous tissue. In addition, repeated use of insulin pen needles is commonly seen among patients with diabetes and is linked with LH $[3,8]$. The association is thought to be due to damage of the needle tip, breakage and removal of lubricant. Mechanical deformation of re-used needles is confirmed by high magnification levels under the electron microscope [9]. Repeated needle use increases the risk of infection. Growth of microflora (Staphylococcus epidermidis) was found at a higher percentage in the skin of patients who reuse the needles [10], and development of peripheral abscess in subjects who reuse insulin syringes has been reported [11].

In addition to the re-use of needles, lack of rotation of injection sites and use of limited injection areas have a well-known association with development of LH [3]. Proper rotation of injection sites and avoiding needle reuse result in prevention or pronounced reduction of $\mathrm{LH}$ $[12,13]$.

The slowing effect of LH on insulin absorption is known to be of significant clinical importance. It results in an erratic absorption of insulin and is directly associated with impaired glycemic control [14]. In addition to the reduced absorption, LH raises within-subject uptake variability 3-5 fold [15]. Reduction of LH is proven to improve glycemic control $[12,13]$.

The main principles of proper injection techniques apply to insulin infusion. Studies on patients using insulin pump therapy reveal multiple dermatologic complications related to use of insulin infusion sets $[16,17]$. Of those complications, LH was found to be the most common [18].

We aimed to explore the injection and infusion routines in a cohort of children and adults with diabetes. We also aimed to study the impact of improper techniques on development of LH and glycemic control.

\section{METHODS}

The study was undertaken at the Endocrinology Department at Mafraq Hospital and was approved by the Mafraq Hospital Research \& Ethics Committee. Children ( $>8$ years) and adults with type 1 diabetes on insulin injection or insulin pump therapy were eligible to participate in the study. Patients with type 2 diabetes were excluded. All procedures performed in this study were in accordance with the Mafraq Hospital Research \& Ethics Committee 
and 1964 Helsinki Declaration and its later amendments.

All participants on insulin injections were using insulin pens. All enrolled children on insulin injections used 4-mm needles. Adults were using 4- or 5-mm needles for insulin injections.

Participants were either seen in the outpatient department during a routine follow-up or were in-patients. Subjects were approached by the study team member to participate, and those who consented were enrolled. Adults and parents of children were asked to sign a consent for participation.

Subjects' demography and diabetes history were obtained from medical records [age, duration of diabetes, insulin total daily dose (TDD)]. Patients were interviewed by a study team member and asked to fill in a questionnaire on insulin injection/infusion routines. Participants were examined by a trained diabetes educator for sites of injection/infusion and their related skin abnormalities. Technique for detecting lipohypertrophy utilized inspection and palpation of injections areas as described by Gentile et al. [19]. All participants had a point of care capillary HbA1c on the day of enrollment.

The areas and choices enquired about in the questionnaire were:

1. Preferred injection/infusion site: abdomen, thighs, arms, buttocks, no preference.

2. Frequency of needle change: at each injection, daily, longer.

3. Complications faced with insulin infusion site: bleeding, bruising, infection, allergy, leakage, discoloration.

4. Frequency of rotating injection/infusion site: at each injection, daily, longer, rarely. The questionnaire was validated by using it in a group of patients who were not participating in the study and a group of hospital staff.

\section{Statistical Analysis}

SPSS software was used to perform the data analysis. Descriptive statistics, frequencies and rankings were obtained. Chi-squared analysis was performed where appropriate for contingency tables. Log linear analysis and ANOVA were used for the analysis of individual parameters, and multiple regression and correlation analyses were used for multi-parametric analysis. Two-tailed tests were used in all analyses.

\section{RESULTS}

\section{Demographic Characteristics of the Study Population}

One hundred four children with type 1 diabetes were enrolled in the study; 54 were on multiple daily injection (MDI) and 50 on insulin pump therapy. Mean age $(\mathrm{SD})$ was $12.11( \pm 4.1)$ with a duration of diabetes of $4.08( \pm 3.58)$ years. The mean (SD) HbA1c was 8.4 ( \pm 1.25$)$ $(68 \mathrm{mmol} / \mathrm{mol})$. The duration of insulin pump use was $2.36( \pm 1.95)$ years. Mean TDD of insulin was $40.26( \pm 27.6)$ units (equivalent to $0.93 \mathrm{U} / \mathrm{kg} /$ day).

The adult study population consisted of 65 subjects. All were on MDI. Mean (SD) age was $54.65( \pm 16.04)$ years. They had diabetes for a duration of $15.58( \pm 8.74)$ years. The TDD of insulin was 71.03 ( \pm 51.19 ) (equivalent to 0.90 $\mathrm{U} / \mathrm{kg} /$ day) and mean HbA1c was 7.6\%. $( \pm 1.11)$ (60 mmol/mol) (Table 1).

\section{Insulin Injection and Infusion Sites}

Of the children on MDI, for 27 (50\%), arms were the preferred site of injection, while thighs were the preferred site of injection in 19 (35.2\%). In eight patients, the abdomen was the preferred site, and none chose the buttocks as the preferred site for injection.

Children on pumps scored the abdomen as the preferred site for infusion set insertion (51\%) followed by the legs in $26 \%$. The buttocks and arms were preferred by $10 \%$ and $6 \%$, respectively, with the remaining $7 \%$ having no insertion site preference. In the adult group, the thighs and abdomen were equally preferred for injection. Twenty-four (37\%) participants indicated that the thighs and abdomen are the preferred site each. None of the participants chose the buttocks as the preferred site, while in 
Table 1 Study population demography

\begin{tabular}{lcc}
\hline & Children mean (SD) & Adults mean (SD) \\
\hline Number & $104(54 \mathrm{MDI}, 50$ pumps) & 65 (all MDI) \\
Duration of diabetes (years) & $4.08(3.58)$ & $14.58(8.74)$ \\
Age (years) & $12.11(4.1)$ & $54.65(16.04)$ \\
Duration of pump use (years) & $2.36(1.95)$ & N/A \\
TDD (IU) & $40.26(27.6)$ & $71.03(51.19)$ \\
Weight (kg) & $43.37(17.19)$ & $78.31(20.76)$ \\
HbAlc $(\%)$ & $8.39(1.25)$ & $7.6(1.11)$ \\
\hline
\end{tabular}

12 , the arms were the preferred site. Five did not have one specific preferred site.

\section{Injection and Infusion Site Rotation}

Thirty-nine $(72.2 \%)$ children on MDI rotate their site at every injection; $10(18.5 \%)$ rotate every day, while $5(9.3 \%)$ rotate at a lower frequency. In adults, 53 (81.5\%) participants replied that they rotate their injection site for every injection. Seven (10.7\%) indicated that they rotate their injection sites daily, and five $(7.7 \%)$ rotate less frequently than daily. None of the participants indicated complete lack of rotation of sites (Table 2). Thirty-seven (74\%) children on insulin pump therapy rotate the infusion site every 2-3 days. Ten (20\%) and three $(6 \%)$ rotated the infusion site every 4-6 days and weekly, respectively (Table 3).

\section{Frequency of Injection Needle Use and Infusion Set Changing}

In children with MDI, 90\% use a new needle with every injection. Of the adults, 55 (84.5\%) change their needles at every injection, while 7 (10.8) change their needles daily and 2 (3.1\%) change it weekly or longer. Of those who do not change needles for every injection, the majority indicated that injection with a used needle is more painful. Seven of the nine adults (77\%) who do not change needles at every injection indicated that they bruise and bleed more often with the re-used needles.

Thirty-nine (78\%) children on insulin pump therapy change the infusion set every $2-3$ days as per the manufacturer's recommendation. Nine (18\%) change it every 4-6 days, while two (4\%) change it weekly (Table 3).

\section{Lipohypertrophy Prevalence}

Thirty-three (61\%) children on MDI did not have LH when examined, while 21 (39\%) had $\mathrm{LH}$ at varying sites. Arms were the most common site for $\mathrm{LH}$, which was seen in nine $(42.8 \%)$ subjects followed by the thighs in seven (21\%) and abdomen in one subject. Four (19\%) subjects had LH at multiple sites: arms, thighs and

Table 2 Injection site rotation and association with $\mathrm{LH}$ in adults and children

\begin{tabular}{llcllc}
\hline Injection site rotation routine & \multicolumn{2}{l}{ Lipohypertrophy $($ adults) } & & \multicolumn{2}{l}{ Lipohypertrophy (children) } \\
\cline { 2 - 3 } \cline { 5 - 6 } & No & Yes & & No & Yes \\
\hline Rotate every injection & $38(71.7 \%)$ & $15(28.3 \%)$ & & $28(71.8 \%)$ & $11(28.2 \%)$ \\
Rotate daily & $3(42.9 \%)$ & $4(57.1 \%)$ & & $4(40 \%)$ & $6(60 \%)$ \\
Rotate less often & $3(60 \%)$ & $2(40 \%)$ & & $1(20 \%)$ & $4(80 \%)$ \\
\hline
\end{tabular}


Table 3 Frequency of changing and rotating infusion set sites in children on insulin pump therapy

\begin{tabular}{llll}
\hline & $\begin{array}{l}\text { Frequency of changing } \\
\text { infusion set }\end{array}$ & $\begin{array}{l}\text { Frequency of rotating } \\
\text { infusion site }\end{array}$ & LH \\
\hline Every 2-3 days & $39(78 \%)$ & $37(74 \%)$ & $32 \%$ \\
Every 4-6 days & $9(18 \%)$ & $10(20 \%)$ & $46 \%$ \\
Weekly & $2(4 \%)$ & $3(6 \%)$ & \\
Total & 50 & & $P=0.58$ \\
\hline
\end{tabular}

abdomen. Of the pump users, 18 had LH (36\%). All were at the abdomen.

In the 65 adults examined, 21 (32.3\%) had LH. Abdomen was the most common site for LH with 14 of the 21 showing $\mathrm{LH}$ at that site either in isolation or among LH in other sites. There was no difference of the lipohypertrophy prevalence in relation to the duration of diabetes.

\section{Relationship Between Lipohypertrophy and Glycemic Control}

Children who did not have LH had a mean (SD) HbA1c of $7.9( \pm 1.02)(63 \mathrm{mmol} / \mathrm{mol})$, while HbA1c for those who had LH was 9.0 (1.31) (75 mmol/mol). This difference was statistically significant $(P<0.001)$. In adults, mean (SD) HbA1c was $7.1( \pm 0.9)(54 \mathrm{mmol} / \mathrm{mol})$ and 8.5 $( \pm 0.83)(69 \mathrm{mmol} / \mathrm{mol})$ in patients who had or did not have $\mathrm{LH}$, respectively. The difference was statistically significant $(P<0.001)$.

\section{Association Between Lipohypertrophy and TDD}

Children who had LH used a mean of 34.9 (19.8) units of insulin a day (equivalent to $0.80 \mathrm{U} / \mathrm{kg} / \mathrm{day}$ ) compared with those with no $\mathrm{LH}$ who used 43.7 (30.5) (equivalent to $1.0 \mathrm{U} /$ $\mathrm{kg} /$ day). The difference was not statistically significant $(P=0.246)$. In adults, the mean insulin was 73.8 (74.6) and 69.7 (36) for those who did and did not have LH, respectively. The difference was not statistically significant $(P=0.765)$.

\section{Lipohypertrophy and Frequency of Rotation in MDI and Pump Therapy}

In children, there was an association between the presence of LH and the frequency of rotation; $28.2 \%$ of those who rotate every injection have $\mathrm{LH}$, while $60 \%$ of those who rotate only every day have $\mathrm{LH}$ and $80 \%$ of those who rotate at a longer frequency. These differences are significant at $P=0.026$. In the adult group, there was a trend toward the presence of LH being associated with the frequency of rotation, too; $28.3 \%$ of those who rotate every injection have $\mathrm{LH}$, while $57.1 \%$ of those who rotate only every day have LH. However, unlike among the children, these differences were not statistically significant $(P=0.287)$ (Table 2$)$.

Among the pump users, of the 37 participants who rotate the infusion site every 2-3 days, 12 (32\%) had LH, while $67 \%$ of those who rotated weekly had LH. Unlike the MDI group, there was no clear association between the presence of LH and frequency of rotation. Differences were not significant $(P=0.587)$ (Table 3).

\section{Needle Re-Use, Infusion Set Change Frequency and Lipohypertrophy}

In children and adults, there was no association between LH and reuse ( $P=0.866$ and $P=0.523$, respectively). However, the very low number of re-users made it difficult to show any relationship. Similarly, no association was observed between the prevalence of $\mathrm{LH}$ and the frequency of the infusion set changes $(P=0.85)$ (Table 3). 


\section{Skin Complications in Insulin Pump Users}

Allergic reaction was reported by 33 participants, bleeding by 30 and insulin leakage by 19 . Fifteen patients reported bruising, 11 reported discoloration, and 7 reported infection at the site of insertion of infusion sets. Eighty percent of participants reported a combination of various complications.

When examined by the study team members, 23 (46\%) had no skin complications and 18 (36\%) had LH. Nodules, allergy marks and hyperpigmentation were seen in $4(8 \%)$ and 3 $(6 \%)$, respectively.

\section{DISCUSSION}

It has been reported that the frequency of LH remains high and is more frequently seen in children than adults [3]. This is the case despite the generally lower duration of diabetes and injection and lower absolute TDD of insulin in children. This observation led to the conclusion that the practice of injecting in a small area due to limited injection space in smaller bodies might be the reason for the higher frequency of the LH [3]. In our cohort, 39\% of children had LH compared with $32 \%$ of the adult group. The presence of LH and the practice of injecting into LH were associated with higher HbA1c values [3]. Our results agree with this evidence as we observed higher HbA1c in both children and adults who had LH. The difference was statistically significant $(P<0.001)$. Reduction of LH by taking appropriate measures on injection is proven to improve glycemic control [12, 13], hence the importance of its detection and prevention.

It was reported that LH is significantly less common in overweight and obese patients $[16,20]$. However, detection of LH requires both examination and palpation of injecting sites as some lesions can be more easily felt than seen [21]. Accordingly, all our study participants were examined by trained diabetes educators to confirm LH indicated in the subjective answers in the questionnaire.

The worldwide injection technique questionnaire multivariate analysis of the pediatric cohorts showed an association between LH and lack of site rotation, excessive needle reuse, longer duration of insulin use and higher number of daily injections [3]. Repeated use of insulin needles and lack of injection site rotation result in LH [22]. Similar results were confirmed by Vardar et al. who found an association between the presence of LH and the failure to rotate sites, using small injecting zones, repeatedly injecting into the same location and reusing needles [23]. In our study, we found that the rotation routine was positively associated with the frequency of LH. While $28.2 \%$ of those who rotate every injection had $\mathrm{LH}$, the percentage was doubled in those who rotate sites only every day. The majority of children (80\%) who rotate sites at a longer frequency had LH. The difference was significant $(P=0.026)$.

In adults, there was a trend toward the presence of LH being associated with the frequency of rotation, too; $28.3 \%$ of those who rotate every injection have $\mathrm{LH}$, while $57.1 \%$ of those who rotate only every day have LH. However, unlike children, these differences were not statistically significant $(P=0.287)$ (Table 2). This observation could be attributed to the small sample size and the large SD. The sites of LH in patients injecting insulin are variable. Omar et al. showed that prevalence of LH was more commonly seen in the arms compared with thighs, which were less frequently used as injection sites [20]. In our study, arms were the preferred site for injection and the most common site for LH in children followed by thighs and abdomen. Nineteen percent of the children had LH at multiple sites: arms, thighs and abdomen. In contrast, LH was more commonly seen in the abdomen and thighs in adults in whom thighs and abdomen were more commonly used. The observation of the association of the LH site being the most common site of injection is also seen in pump users. Thirty-six percent of pumpers had LH, and all the LH areas were in the abdomen, which was voted the favorite site for infusion set insertion.

There is a strong tendency for patients who reuse needles to have more hypertrophic lesions. It was reported by the European 
epidemiologic study on the technique of insulin injection that the risk of $\mathrm{LH}$ in patients reusing needles is $31 \%$ higher with $70 \%$ of patients who re-use needles having LH [24]. A Spanish study showed that the relative risk of LH doubled when the needle was used 3-5 times but went up fivefold with use over 5 times [22].

We found a low rate of needle re-use in our study with $90 \%$ of children and $85 \%$ of adults changing their needle at every injection. Of those who do not change needles at every injection, the majority commented that injection with a used needle is more painful. Seven of the nine adults who do not change needles at every injection indicated that they bruise and bleed more often with the re-used needles. As the rate of needle re-use was low, we were not able to establish its association with the prevalence of $\mathrm{LH}$.

The rate of skin complication of pump users in our study seems to be lower than those found in an earlier study in children and adolescents [16]. In that study, $94 \%$ had scars, $66 \%$ had erythema, $62 \%$ had nodules and $42 \%$ had LH. Similarly, in another study with 78 children on insulin pump therapy, $46 \%$ of these reported lipohypertrophic areas at the insertion site [17]. Of our patients on pump, 36\% had LH, $8 \%$ had nodules and $14 \%$ had either hyperpigmentation marks or nodules. In a survey of adult patients on insulin pump therapy, it was found that the most common infusion site problem was $\mathrm{LH}$ (26.1\%). This complication occurred more often in those with long duration of pump therapy [18]. In our cohort, allergic reaction to adhesives was the most common complication of pump insertion reported by patients followed by bleeding, insulin leakage, bruising, discoloration and site infection. On examination, $\mathrm{LH}$ was detected in $36 \%$ of patients. Thirty-nine (78\%) children on insulin pump therapy change the infusion set every 2-3 days as per the manufacturer's recommendation. Nine (18\%) change it every 4-6 days, while two (4\%) change weekly. We found no association between the prevalence of $\mathrm{LH}$ and the frequency of the infusion set changes $(P=0.85)$ (Table 3). However, $54 \%$ of patients indicated that blood glucose readings tend to go up by the last day of insertion if they exceeded 3 days in changing the infusion set. This observation was reported before by Clausen et al., who examined the effect of subcutaneous catheter insertion on adipose tissue blood flow and insulin absorption [25]. Total daily dose of insulin did not seem to correlate with LH prevalence in our study. Children and adults who had a higher TDD/kg/day than others did not have a higher prevalence of LH. Comparing children and adults, we found that children had higher prevalence of lipohypertrophy despite the fact that they had a lower absolute total daily dose of insulin and a comparable total daily dose per $\mathrm{kg}$ of weight. Overall, neither the total amount of insulin injected/infused nor the frequency of rotation of the infusion sites in pump users enhanced the development of LH. These observations favor the effect of trauma on development of the $\mathrm{LH}$ rather than the anabolic effect of insulin on the subcutaneous tissue.

Our study highlights important findings that are not confined to our cohort but can be applicable to patients with diabetes globally. In the current era of modern medicine, health care professionals might be carried away by the advanced technology at the expense of the basics rules of education. Our study's strength is that it included both children and adults and explored both MDI and insulin pump therapy. In addition, subjective answers of questionnaire were confirmed by physical examination by trained diabetes educators. However, it has limitations particularly in relation to the relatively small number of participants and the single-center origin of data. In addition to exploring the glycemic control in relation to the injection/infusion routine, it would be useful to examine the impact on hypoglycemia and acute hyperglycemic complications, which we plan to research in a future study.

\section{CONCLUSION}

We conclude that assessment of injection/infusion routines and examination of injection sites remain a crucial part of routine care offered to patients with diabetes. While basic education of proper injection/infusion techniques does not require major changes in health care 
systems, allocating time for reassessment within busy clinic schedules might be a challenge. Our recommendations in relation to injection techniques are in concordance with the newly published multi-country survey practice implications by Kalra et al. [26].

\section{ACKNOWLEDGEMENTS}

We thank the participants of the study for their participation.

Funding. No funding was sought to undertake the study. The Article Processing Charges were funded by the author.

Authorship. All named authors meet the International Committee of Medical Journal Editors (ICMJE) criteria for authorship for this article, take responsibility for the integrity of the work as a whole, and have given their approval for this version to be published.

Author Contribution. Asma Deeb designed the study, collated data and wrote the manuscript. Layla Abdelrahman, Mary Tomy and Shaker Suliman collected data on demography and diabetes history, examined the study participants and performed the HbA1c. Mariette Akle designed the questionnaire and interviewed subjects. Mike Smith advised on study design and reviewed the manuscript. Ken Strauss performed the statistical analysis and reviewed the manuscript.

Disclosures. Asma Deeb, Layla Abdelrahman, Mary Tomy, Shaker Suliman, Mariette Akle, Mike Smith and Ken Strauss have no conflict of interest to declare.

Compliance with Ethics Guidelines. All procedures performed in this study were in accordance with Mafraq Hospital Research \& Ethics Committee and with the 1964 Helsinki Declaration and its later amendments.

Data Sharing. Data sets during and/or analyzed during the current study are available from the corresponding author on reasonable request.

Open Access. This article is distributed under the terms of the Creative Commons Attribution-NonCommercial 4.0 International License (http://creativecommons.org/licenses/ by-nc/4.0/), which permits any noncommercial use, distribution, and reproduction in any medium, provided you give appropriate credit to the original author(s) and the source, provide a link to the Creative Commons license, and indicate if changes were made.

\section{REFERENCES}

1. Guerci B, Sauvanet JP. Subcutaneous insulin: pharmacokinetic variability and glycemic variability. Diabetes Metab. 2005;31:4S7-4S24.

2. Frid AH, Kerugel G, Grassi G, Halimi S, Hicks D, Hirsch LJ, Smith MJ, Welhoener R, Bode BW, Hirsch IB, Karla S, Ji L, Strauss KW. New insulin delivery recommendations. Mayo Clin Proc. 2016;91(9):1231-55.

3. Frid AH, Hirsch LJ, Menchior AR, Morel DR, Strauss $\mathrm{KW}$. Worldwide injection technique questionnaire study: injecting complications and role of the professional. Mayo Clin Proc. 2016;91(9):1224-30.

4. Partanen TM, Rissanen A. Insulin injection practices. Pract Diab Int. 2000;17:252-4.

5. Strollo F, Gentile S. Comment on the new Indian injection technique recommendations: critical appraisal of the real-world implementation of the current guidelines. Diabetes Ther. 2017;8(3):507-11.

6. Fujikura J, Fujimoto M, Yasue S, Noguchi M, et al. Insulin-induced LH: report of a case with histopathology. Endocr J. 2005;52(5):623-8.

7. Gentile S, Strollo F, Della Corte TD, Marino G, Guarino G, the Italian Study Group on Injection Techniques. Skin complications of insulin injections: a case presentation and a possible explanation of hypoglycaemia. Diabetes Res Clin Pract. 2018;138:284-287.

8. Ginsberg B, Strauss K. Has RoboCop got diabetes? Response to Berger et al. Diabetes Care. 2004;27:1851-2. 
9. Look D, Strauss K. Nadeln mehrfach verwenden? Diab J. 1998;10:S31-4.

10. Misnikova IV, Dreval AV, Gubkina1 VA, Rusanov $\mathrm{EV}$. The Risk of repeated use of insulin pen needles. J Diab. 2011;1:1.

11. Paily R. Perinephral abscess from insulin syringe reuse. Am J Med Sci. 2004;327:47-8.

12. Thow JC, Johnson AB, Marsden S, Taylor R, Home $\mathrm{PH}$. Morphology of palpably abnormal injection sites and effects on absorption of isophane (NPH) insulin. Diab Med. 1990;7:795-9.

13. Teft G. LH: patient awareness and implications for practice. J Diab Nurs. 2002;6:20-3.

14. Chowdhury TA, Escudier V. Poor glycaemic control caused by insulin induced LH. BMJ. 2003;327:383-4.

15. Famulla S, Hövelmann U, Fische A, et al. Insulin injection into lipohypertrophic tissue: blunted and more variable insulin absorption and action and impaired postprandial glucose control. Diab Care. 2016;39:486.

16. Conwell LS, Pope E, Artiles AM, Mohanta A, Daneman A, Daneman D. Dermatological complications of continuous subcutaneous insulin infusion in children and adolescents. J Pediatr. 2008;152(5):622-8.

17. Schober E, Rami B. Dermatological side effects and complications of continuous subcutaneous insulin infusion in preschool-age and school-age children. Pediatr Diab. 2009;10:198-201.

18. Pickup JC, Yemane N, Brackenridge A, Pender S. Nonmetabolic complications of continuous subcutaneous insulin infusion: a patient survey. Diab Tech Ther. 2014;16(3):145-9.
19. Gentile S, Guarino G, Giancaterini A, Guida P, Strollo F, AMD-OSDI Italian Injection Technique Study Group. A suitable palpation technique allows to identify skin lipohypertrophic lesions in insulintreated people with diabetes. Springer plus. 2016;5:563.

20. Omar MA, El-Kafoury AA, El-Araby RI. LH in children and adolescents with type 1 diabetes and the associated factors. BMC Res Notes. 2011;4:290.

21. Seyoum B, et al. Systematic inspection of insulin injection sites for local complications related to correct injection technique. Trop Doct. 1996;26:159-61.

22. Blanco M, Hernández MT, Strauss KW, Amaya M. Prevalence and risk factors of $\mathrm{LH}$ in insulin-injecting patients with diabetes. Diab Metab. 2013;39(5):445-53.

23. Vardar, et al. Incidence of LH in diabetic patients and a study of influencing factors. Diabetes Rec Clin Pract. 2007;77:231-6.

24. Strauss K, De Gols H, Hannet I, Partanen TM, Frid A. A pan-European epidemiologic study of insulin injection technique in patients with diabetes. Pract Diab Int. 2002;19:71-6.

25. Clausen TS, Kaastrup P, Stallknecht B. Effect of insulin catheter wear-time on subcutaneous adipose tissue blood flow and insulin absorption in humans. Diab Technol Ther. 2009;11(9):575-80.

26. Kalra S, Hirsch LJ, Frid A, Deeb A, Strauss KW. Pediatric insulin injection technique: a multicountry survey and clinical practice implications. Diabetes Ther. 2018;9(6):2291-302. 